\title{
Boiling Point Estimation Program Especially for Aromatic Compounds Supplementing Joback Method
}

\author{
Shin Hyo Bang, Seung Jae Lim, and Taeseon Yoon
}

\begin{abstract}
Recently, the computer technology advanced profoundly that the application has no limit. Equipped with programming, we wanted to make a program which is related to chemistry. While finding an appropriate adoption of computer programming to chemistry, we thought that estimating boiling point might be the one. Boiling points have regularity which allows us to make a program that estimates boiling points. Searching, we found an appropriate program which is based on Joback Method on a site. The program had a weakness; the basic theory, the Joback Method, which the program relies on has a few errors. The biggest problem was the fact that the method does not differentiate aromatic compounds from aliphatic compounds. Thus, on this paper, we tried to provide another formula that could explain the boiling points tendency for the aromatic compounds.
\end{abstract}

Index Terms-Aromatic, boiling point, Pirika, Joback method.

\section{INTRODUCTION}

In this paper, we are going to suggest a computer related model which explains molecular interactions. Chemistry and informatics seem an ill-assorted couple. Chemistry is the scientific study of the structure of substances and of the way that they react with other substances. Informatics, by the way, is a study of the computer and statistics. We cannot discover chemical mechanisms by computer works. A standard, and traditional procedure for researching the field of chemistry would be doing experimental works. However, by analyzing the chemical patterns using informatics, we at least expect to demonstrate existing laws, or even gain new ones. The informatics could be used as a tool for chemistry.

The importance of computer in the field of Chemistry is increasing; this year, three U.S. scientists won the Nobel chemistry prize on for pioneering work on computer programs. Similarly, we wanted to adopt a computer program into the world of molecules [1].

\section{EXPERIMENT OBJECT}

Boiling point is an important criterion for molecular interactions, as in [2]. The higher the boiling point of the matter is, the stronger the inter-molecular force is. Table I efficiently suggests the idea.

Hydrogen cyanide has a higher boiling point than that of acetylene. This means hydrogen cyanide has a stronger interaction between molecules. This also fits the laws that rule

Manuscript received December 4, 2013; revised February 7, 2014.

The authors are with the Hankuk Academy Foreign Studies, South Korea (e-mail: bang9704@naver.com, bingdark@naver.com, tsyoon@hafs.hs.kr). the molecular interactions. The molecules act under a series of certain chemical laws which include van der Waals forces, et cetera. We wanted to simulate these laws on the computer space. There have been a few attempts to analyze the boiling point patterns of chemical compounds beside us. Yet, former attempts could not effectively explain significant errors. Our object is to modify existing program models and reduce the gap between real boiling point and expected boiling point which is gained from the program.

TABLE I: BOILING POINT COMPARISONS

\begin{tabular}{|c|c|c|c|}
\hline & $\begin{array}{l}\text { Molecular } \\
\text { Weight }\end{array}$ & Polarity & $\begin{array}{l}\text { Boiling } \\
\text { Point(degrees } \\
\text { celsius) }\end{array}$ \\
\hline Hydrogen Cyanide & 27 & $\mathrm{O}$ & 26 \\
\hline Acetylene & 26 & $X$ & -83 \\
\hline
\end{tabular}

\section{EXISTING EstimATION METHOD AND APPLICATION}

\section{A. Explanation}

The existing estimation method is called Joback Method. The Joback method predicts eleven important and commonly used pure component thermodynamic properties from molecular structure only, as in [3]. Group contribution method is essentially used in Joback Method. This uses basic structural information of a chemical molecule like a list of simple functional groups. Adding parameters to these functional groups, we can calculate thermophysical properties as a function of the sum of group parameters. Methane is the simplest hydrocarbon. Every arm of the central $\mathrm{C}$ bonds with that of Hydrogen. Let's assume a functional group such as hydroxyl group replaced hydrogen. The boiling point should vary because hydroxyl group possesses different chemical property than hydrogen. Without doubt, Joback method gives different values given to hydroxyl group than that of hydrogen. There should be a discrepancy between expected boiling points of the two (see Table II).

\section{B. Factors}

The degree of electronic delocalization is the most fundamental element that determines the interaction between molecules. Bipolarity and molecular mass affect it. Let's assume there are two molecules that have similar mass. Compared with non-bipolar molecule, bipolar one can exchange electrical force. Thus, the higher the degree of bipolarity is, the higher the boiling point it would have. This is the reason why Joback method gives different values to each functional group. For instance, among Halogen group, the fluorine group, which is well known for its great electro negativity, is given higher value than chlorine. Molecular 
mass means the number of protons because atoms are usually neutrally electronic delocalized. There is another reason for the importance of molecular mass. The universal gravitation of heavier molecules is larger than that of lighter ones, which leads to the higher boiling point. Joback method also accounts for this. In the Joback method's formula, as the number of functional groups that are added increases, the constant value (Tb) for each function group is multiplied and applied to the calculation. The shape of molecule also affects the interaction. The increasing molecular surface leads to stronger bond. Normal-pentane, for instance, has a higher boiling point than neo-pentane. That is because the latter one has a round shaped electron cloud, whereas the former has a straightened one (see Fig. 1 and Fig. 2).

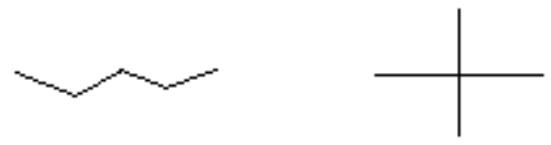

Fig. 1. Normal-pentane and neo-pentane.

Equation (1) below is the Joback method's boiling point estimating formula:

$$
T b=198+\sum T b, i
$$

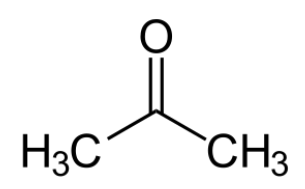

Fig. 2. Acetone is separated into three groups in the Joback method: two methyl groups $\left(-\mathrm{CH}_{3}\right)$ and one ketone group $(\mathrm{C}=\mathrm{O})$. Since the methyl group is present twice, its contributions have to be added twice.

TABLE II: GROUP CONTRIBUTIONS

\begin{tabular}{|c|c|}
\hline Non-ring Groups & $\mathrm{Tb}$ \\
\hline$-\mathrm{CH} 3$ & 23.58 \\
\hline$-\mathrm{CH} 2-$ & 22.88 \\
\hline$>\mathrm{CH}-$ & 21.74 \\
\hline$>\mathrm{C}<$ & 18.25 \\
\hline$=\mathrm{CH} 2<$ & 18.18 \\
\hline$=\mathrm{CH}-$ & 24.96 \\
\hline$=\mathrm{C}<$ & 24.14 \\
\hline$=\mathrm{C}=$ & 26.15 \\
\hline$\Xi \mathrm{CH}$ & 9.20 \\
\hline$\Xi C-$ & 27.38 \\
\hline Oxygen Groups & $\mathrm{Tb}$ \\
\hline -OH(alcohol) & 92.88 \\
\hline -OH(phenol)- & 76.348 \\
\hline -O-(nonring) & 22.42 \\
\hline$-\mathrm{O}-($ ring) & 31.22 \\
\hline$>\mathrm{C}=\mathrm{O}$ (nonring) & 76.75 \\
\hline$>\mathrm{C}=\mathrm{O}$ (ring) & 94.97 \\
\hline $\mathrm{O}=\mathrm{CH}-($ aldehyde $)$ & 72.24 \\
\hline$-\mathrm{COOH}($ acid $)$ & 169.09 \\
\hline -COO-(ester) & 81.10 \\
\hline
\end{tabular}

\section{SHORTCOMINGS OF EXISTING ESTIMATION METHOD AND APPLICATION}

\section{A. Lists of Problems}

Joback method predicts boiling points by eleven important and commonly used pure component thermodynamic properties from molecular structure. However there are some shortcomings exist in Joback method. Recently, newer developments of estimation methods have shown that the quality of the Joback method is limited. Eleven groups don't cover many common molecules sufficiently.

1) Joback assumed that there is no group interaction, but only additive contribution exists. However, group interaction exists and this factor affect molecule structure, electron cloud and etc. Ignoring group interaction could be a severe for small and large compounds due to group interaction contribute large ratio of small-sized compounds and so many complex interaction exists in large-sized compounds.

2) Furthermore, the Joback method does not differentiate aromatic compounds from normal ring containing components. This shortcoming leads to increased deviations between estimated normal boiling points and experimental normal boiling points.

As in [4], aromatic is generic of an organic compounds which contain benzene rings in the molecule. Aliphatic is a general term of organic compounds which carbon atoms in the molecule do not contain ring structure. This is severe problem as aromatic and aliphatic differ strongly. These shortcomings lead to high deviations for large and small molecules and an acceptable good estimation only for mid-sized components.

Recent advanced data banks like the Dortmund Data Bank (factual data bank for thermodynamic and thermophysical data) or the DIPPR data base have a much more coverage.

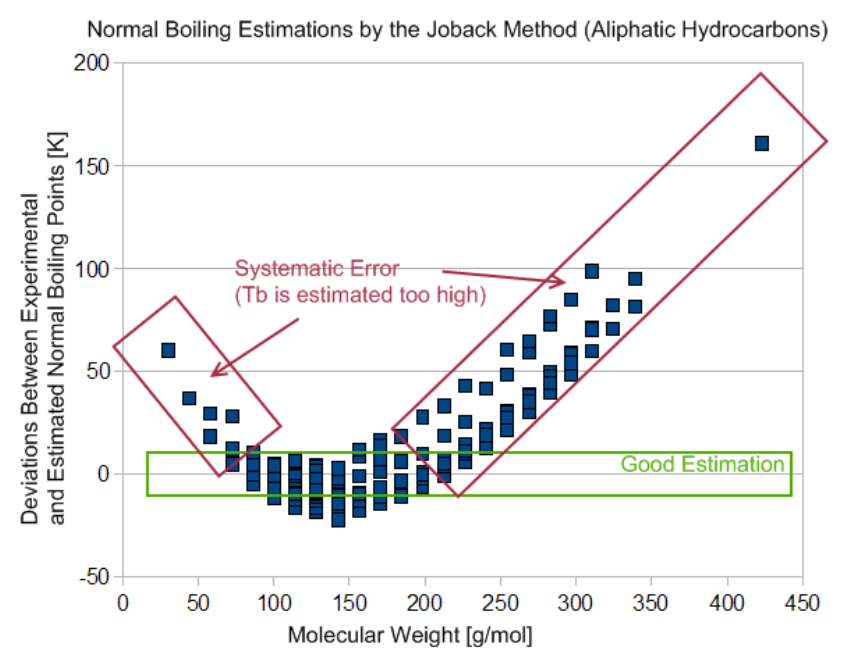

Fig. 3. Deviations between predicted normal boiling points and experimental data.

Fig. 3 shows the deviations between predicted normal boiling points (Joback method) and experimental data taken from the Dortmund Data Bank. There are some systematic errors according to Fig. 1. Most of large deviation gap occurred in molecular weight between approximately $0 \sim 80(\mathrm{~g} / \mathrm{mol})$ and $200 \sim 450(\mathrm{~g} / \mathrm{mol})$. This proves that Joback method has inappropriate estimations for large and small molecules. However, good estimation occurred in molecular weight between approximately 100 200(g/mol) which are mid-sized molecules. 


\section{EXPERIMENTS}

We found boiling points of 12 aromatic compounds according to [5], [6]. Most of them have isotopes, which led us to find mean value of each compound group. And the following Table III shows the result of it.

TABLE III: ARomatic COMPOUNDS AND MEAN VALUES OF BOILING POINTS

\begin{tabular}{lc}
\hline \hline Compounds & Boiling Point(Degrees Celsius) \\
\hline Benzene & 80 \\
Toluene & 110.6 \\
Xylen- & 140.46 \\
& 138.4 \\
Cumene & 144 \\
& 160.45 \\
Naphthalene & 152.4 \\
Methy Naphthalene & 168.5 \\
& 218 \\
Dimethy Naphthalene & 241.75 \\
& 241.5 \\
& 242 \\
Trimethy Naphthalene & 264.96 \\
& 264.4 \\
& 264.4 \\
Trimethyl Anthracene & 263 \\
Anthracene & 266.5 \\
Methyl Anthracene & 283.37 \\
& 285 \\
& 282 \\
& 283.1 \\
& 340 \\
& 356.8 \\
& 363 \\
& 375 \\
& 353.5 \\
& 338.75 \\
& 353.52 \\
& 369.1 \\
& 369.64 \\
& 368.096 \\
& 370.8 \\
& 363 \\
& 374 \\
& 389.66 \\
& 387.64 \\
& 385.28 \\
& 389.73 \\
& 393.24 \\
& 394.5 \\
& \\
&
\end{tabular}

We made a graph using Excel.

Analyzing the graph, we found out that the line is first dimensional. This suggests the boiling point has a direct proportion to the number of benzene rings and methyl groups. Based on the very fact, we drew a foumula that calculates(estimates) the boiling points of the compounds that have one benzene ring(with vaiating number of methyl groups) and none methyl group(with varitating number of benzene rings).

$$
B_{p}=80+120(n-1)+26 r
$$

$n$ : The Number of Benzene Rings

\section{$r$ : The Number of Methyl Groups}

You might easily recognize the similarity between the experimental results and estimated results. The other compounds that have more than one benzene rings and methyl groups would satisfy the formula. We made a program using php language that calculates the boiling point of aromatic compounds based on our formula (see Fig. 4-Fig. 8).

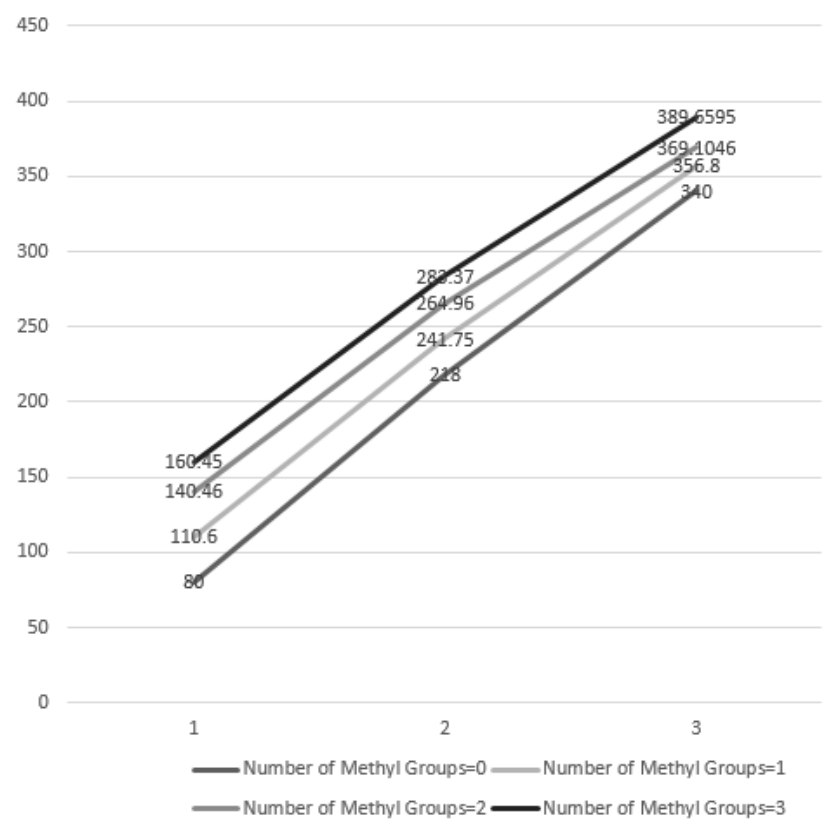

Fig. 4. Experimental boiling points depending on the number of benzene rings.

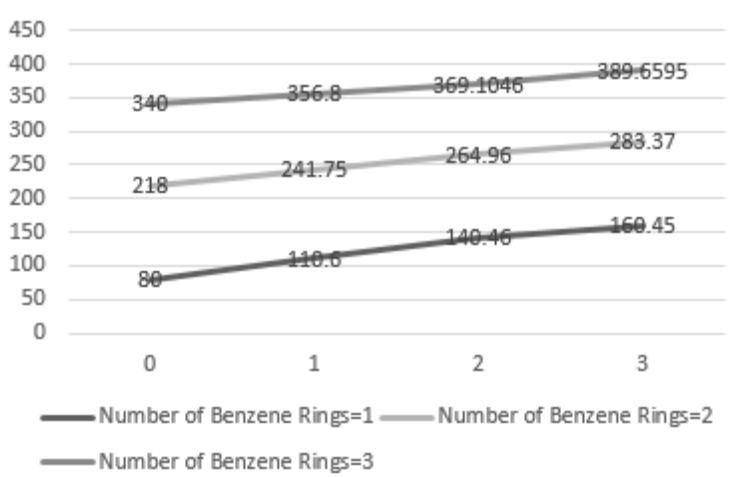

Fig. 5. Experimental boiling points depending on the number of methyl groups.

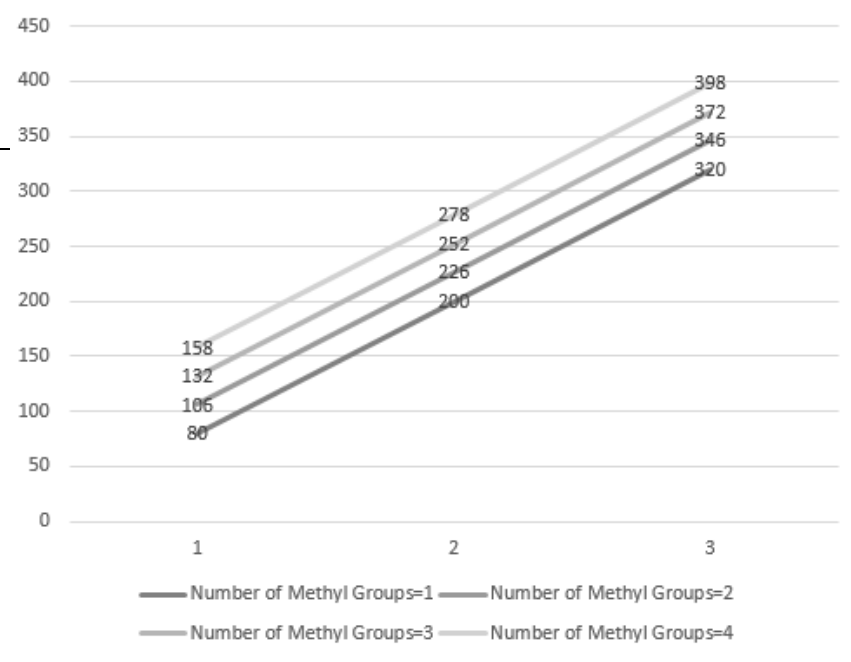

Fig. 6. Estimated boiling points depending on the number of benzene rings. 


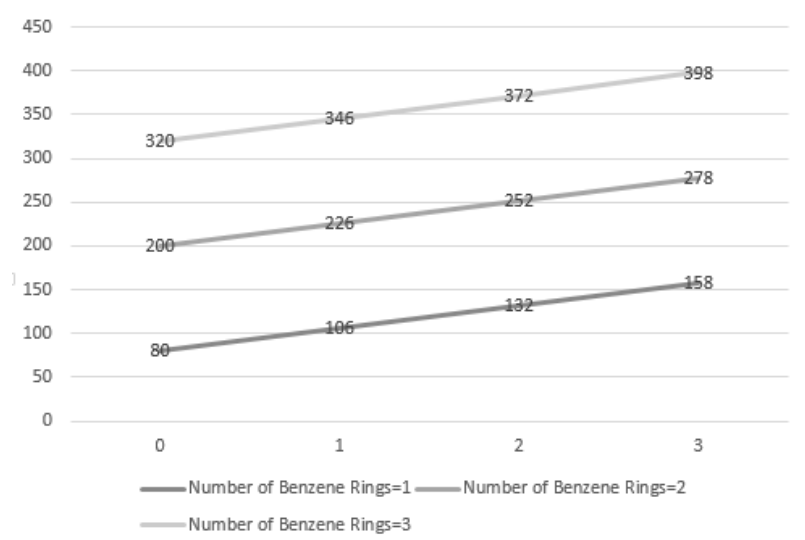

Fig. 7. Estimated boiling points depending on the number of methyl groups.

This is the address for the site: http://125.247.90.14/ boiling/

"Boiling Point Estimation Program for Aromatic Compounds" $B P=80+120(n-1)+26(r)$ " $n$ : number of benzene ring $r$ : number of $\mathrm{CH}_{3}$ "

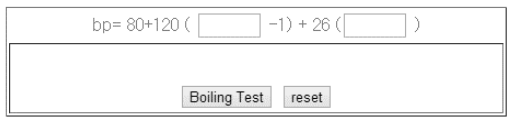

Fig. 8. Boiling point estimation program for aromatic compounds.

\section{CONCLUSION}

\section{A. Results}

This research gained a formula which efficiently accounts for the boiling point of aromatic compounds. The biggest problem that the exiting Joback method does not differentiate aromatic compounds from aliphatic compounds is solved. Furthermore, building a computer related program shows the potential of informatics that could be applied to chemistry

\section{B. Expectations}

Since aromatic compounds' boiling point follows the formula that is gained through the research instead of the Joback method, new boiling point constant for functional groups other than methyl groups should be calculated. Sequent goal is to build more sophisticated and accurate version of the program.

\section{REFERENCES}

[1] A. Murata, K. Tochigi, and H. Yamamoto, "Prediction of vapor-liquid equilibrium from structural formula," in Proc. the 6th International Symposium on Separation Technology -between Japan and Korea(ISST02-JK), PE-119, pp. 107-110, Tokyo, October 4-6, 2002.

[2] S. S. Zumdahl, Chemistry, 8th Edition, ch. 10.1, pp. 460-468.

[3] J. Method. (2008). [Online]. Available: http://wikipedia. org

[4] J. E. McMurry, Organic Chemistry, 8th ed., ch. 15, pp. 572-578, 2011.

[5] Royal Society of Chemistry, "Chemspider: A free chemical structure database providing fast access to over 29 million structures, properties, and associated information," ABI Chemicals, 2011/5/10-2013/5/10, Chem DB, 2008/4/15.

[6] U. Onken, J. Rarey-Nies, and J. Gmehling, "The dortmund data bank: a computerized system for retrieval, correlation, and prediction of thermodynamic properties of mixtures," Int. J. Thermophys., 1989, vol. 10 , no. 3 , pp. $739-747$

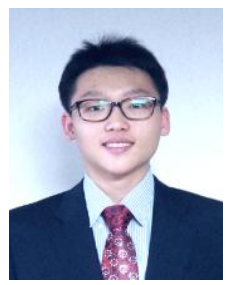

Shin Hyo Bang was born in 1997. He is currenty a student in science major of Hankuk Academy of Foreign Studies, Korea. He is mostly interested in energy resources and has been studying pattern analysis and computer programming and its application to chemistry.

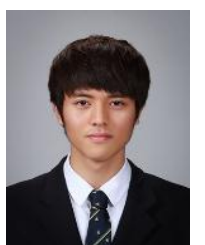

Seung Jae Lim was born in 1996. He is currenty a student in science major of Hankuk Academy of Foreign Studies, Korea. He is mostly interested in biology and has been studying pattern analysis and computer programming and its application to chemistry.

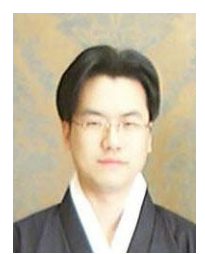

Taeseon Yoon was born in Seoul, Korea, in 1972. He received his $\mathrm{Ph} . \mathrm{D}$. degree in computer education from the Korea University, Seoul, Korea, in 2003.

From 1998 to 2003, he was with EJB analyst and SCJP. From 2003 to 2004, he joined the Department of Computer Education, University of Korea, as a lecturer and Ansan University, as an adjunct professor. Since December 2004, he has been with the Hankuk Academy of Foreign Studies, where he was a computer science and statistics teacher. He was the recipient of the Best Teacher Award of the Science Conference, Gyeonggi-do, Korea, 2013. 